\title{
Retraction Note to: Brain Trauma and Nutritional Support
}

In the book, "Diet and Nutrition in Critical Care" (2015; ISBN: 978-1-4614-7837-9), Springer is retracting chapter 51 entitled "Brain Trauma and Nutritional Support" by Wolfgang A. Wetsch, Bernd W. Böttiger, and Stephan A. Padosch. After carefully examining the material used in the chapter, it was determined the chapter constitutes copyright infringement with regard to a previously published journal article, "Ernährungstherapie bei Schädel-Hirn-Trauma", published in Der Anaesthesist, (C) Springer-Verlag 2012.

The online version of the original chapter can be found at http://dx.doi.org/10.1007/978-1-4614-7836-2_72 